\title{
STRATEGI PENGEMBANGAN PEMASARAN "LAKSA TANGERANG" SEBAGAI SALAH SATU PRODUK WISATA KULINER DI TANGERANG
}

\section{Dhian Tyas Untari}

Budi Satria

Email : tyas_un@yahoo.co.id

\section{Penulis}

Dhian Tyas Untariadalah Dosen pada Fakultas Ilmu Pendidikan dan Pengetahuan Sosial (FIPPS), Universitas Indraprasta PGRI, Jakarta.

Budi Satria adalah Dosen pada Fakultas Matematika dan Ilmu pengetahuan Alam (MIPA) Universitas Indraprasta PGRI, Jakarta

\section{Abstract}

Laksa Tangerang is one exclusive culinary of Tangerang which has potential to be developed as culinary tourism product. Tangerang considering that tourism sector is one of sector that has large enough of foreign exchange earninge even for regional development level or national development level. This research use IF/EF and SWOT Analisys by using primary data obtained from interviews and observations on culinary entrepreneurs and craftsmen and secondary data from related institutions. Through the analisys a marketing strategy in developing laksa Tangerang and is expected to make recommendations in the development of culinary tourism in Tangerang Melalui analisis tersebut diharapkan penelitian dapat menghasilkan sebuah strategi pemasaran dalam mengembangkan laksa Tangerang dan diharapkanju dapat menjadikan rekomendasi dalam pengembangan wisata kuliner di Tangerang.

\section{Kata Kunci}

Pemasaran, Analisis SWOT, Wisata, Kuliner 


\section{LATAR BELAKANG}

Pariwisata merupakan salah satu kegiatan yang menjadi kebutuhan hampir seluruh manusia. Selain itu sektor pariwisata juga merupakan salah satu sektor pembangunan yang mempunyai manfaat ganda atau multiplier effect secara ekonomi bagi pemerintah daerah melalui peningkatan Pendapatan Asli Daerah (PAD) dan ekonomi masyarakat melalui perluasan kesempatan kerja dan peningkatan pendapatan. Di Indonesia sektor wisata merupakan salah satu penyumbang devisa yang signifikan bagi Indonesia. Secara keseluruhan, sektor pariwisata menjadi penyumbang no 5 pada tahun 2008, no 4 pada tahun 2009 dan no 5 pada tahun 2010. Jika dilihat sumbangan sektor non migas, sektor pariwisata menempati urutan 2 dan 3 (Dewi, 2011; 4).

Seiring dengan perubahan global, paradigma pariwisata Indonesia sudah memperlihatkan perubahan yang signifikan. Pada masa lalu spektrum pembangunan pariwisata lebih diorientasikan hanya pada beberapa kawasan penting saja, sementara dilihat dari kecenderungan perubahan pasar global yang lebih mengutamakan sumber daya lokal sebagai destinasi pariwisata (Kardigantara dan Goeltom, 2007). Sehubungan dengan trend wisata tersebut pengembangan wisata kuliner dapat dijadikan sebagai salah satu produk wisata, dimana makanan dengan perspektif kelokalan menjadi mind product dapat meningkatkan perekonomian masyarakat baik sebagai petani bahan baku makanan, pengrajin makanan, sampai dengan mendukung program diversifikasi pangan.

Pariwisata dan makanan merupakan duet ideal, manakala mendampingi kegiatan pariwisata. Sesuai dengan fitrah manusia atau wisatawan yang selalu tak bisa berhenti berkonsumsi. Wisata kuliner menempatkan makanan sekaligus 
sebagai subjek dan media, sebagai destinasi dan alat bagi pengembangan pariwisata (Virna, 2007).

Kota Tangerang adalah sebuah kota yang terletak di Provinsi Banten, Indonesia, tepat di sebelah barat kota Jakarta, serta dikelilingi oleh Kabupaten Tangerang di sebelah utara dan barat. Tangerang merupakan kota terbesar di Provinsi Banten serta ketiga terbesar di kawasan perkotaan Jabotabek setelah Jakarta.

Terkait dengan pengembangan wisata, Tangerang memilik banyak potensi wisata yang dapat dikembangkan salah satunya adalah wisata kuliner. Salah satu produk kuliner khas Tangerang adalah Laksa, dimana laksa merupakan hasil akuliturasi budaya antara budaya China dan Betawi bagian utara. Semua potensi wisata kuliner khususnya produk laksa yang dimiliki oleh kota Tangerang membutuhkan sebuah pengelolaan yang baik sehingga dapat memberikan manfaat. Salah satu pengelolaan yang perlu diperhatikan adalah terkait pemasaran.

Berdasarkan uraian diatas dimana telah disebutkan bahwa secara umum sektor pariwisata merupakan sebuah sektor strategis, disisi lain diketahui juga bahwa keadaan Kota Tangerang yang kaya akan potensi wisata serta potensi pengembangan kuliner, baik sebagai pendukung kegiatan wisata maupun produk yang mempunyai daya tarik wisata tersendiri, maka perlu sebuah penangan yang menyeluruh, terintegrasi dan terus menerus, oleh karena itu perlu sebuah kajian tentang strategi pemasaran laksa sebagai produk wisata kuliner di Kota Tangerang yang dapat dijadikan sebuah acuan dalam mengembangkan wisata kuliner di Kota Tangerang. 


\section{METODE PENELITIAN}

Jenis penelitian yang digunakan adalah penelitian deskriptif. Menurut Sugiyono (2011:35), penelitian deskriptif adalah penelitian yang dilakukan untuk mengetahui nilai variabel mandiri, baik satu variabel atau lebih (independent) tanpa membuat perbandingan atau menghubungkan dengan variabel yang lain. Dalam penelitian ini tidak mengarah pada pengujian hipotesis tetapi lebih mempunyai sudut pandang pada fenomena strategi perusahaan dan data yang terkumpul dalam penelitian ini dengan menggambarkan manajemen strategis untuk memenuhi tujuan perusahaan yang dilihat dari lingkungan internal maupun eksternal tanpa menekankan pada angka.

Penelitian ini dilakukan di Kota Tangerang terkait pengembangan kuliner laksa sebagai produk wisata kuliner. Dasar pertimbangan memilih laksa Tangerang sebagai fokus penelitian adalah 1). Laksa Tangerang merupkan salah satu kuliner khas Tangerang, 2). Kurang dikenalnya laksa Tangerang secara lebih meluas.

\section{Teknik Pengumpulan Data}

Pengumpulan data menurut Hasan (2002:83) merupakan pencatatan peristiwa-peristiwa atau hal-hal atau keterangan-keterangan atau karakteristikkarakteristik sebagian atau seluruh elemen populasi yang akan menunjang atau mendukung penelitian. Pengumpulan data adalah prosedur yang sistematis dan standar untuk memperoleh data yang diperlukan (Nazir, 2003:174).

Metode pengumpulan data merupakan suatu teknik yang dilakukan oleh peneliti dalam mengumpulkan data-data yang diperlukan untuk mendukung penelitian, baik yang berupa data primer maupun data sekunder. Metode 
pengumpulan data yang digunakan dalam penelitian ini dapat dibagi menjadi 2 (dua) kegiatan yaitu ;

\section{a. Survei primer}

Data primer adalah data yang diperoleh dari survei primer, yaitu melakukan studi terhadap permasalahan yang ada dengan mengamati secara langsung kondisi yang berlaku sehingga dapat diketahui kondisi yang ada pada wilayah studi. Adapun jenis data yang diperoleh melalui survei primer pada wilayah studi yaitu laksa sebagai pendukung kegiatan wisata di Tangerang. Untuk memperoleh data primer itu dapat dilakukan beberapa teknik pengambilan data, yaitu sebagai berikut:

\section{- Observasi lapangan.}

Observasi meliputi kegiatan pemuatan perhatian terhadap suatu objek dengan menggunakan seluruh alat indra (Arikunto, 2002:133). Metode pengamatan/ observasi dilakukan dengan mengamati langsung obyek studi untuk mendapatkan informasi-informasi yang akurat mengenai kondisi eksisting obyek penelitian. Metode ini dipergunakan untuk memperoleh data dan informasi, yaitu dengan melakukan pengamatan secara langsung dilapangan serta menyelaraskan antara informasi yang diperoleh dari survei sekunder dengan kondisi di lapangan.

\section{- Wawancara}

Teknik wawancara merupakan pengumpulan data dengan mengajukan pertanyaan langsung oleh pewawancara kepada responden, dimana jawaban-jawaban responden dicatat atau direkam (Hasan, 2002:85). Wawancara yang dilakukan adalah dengan menggunakan teknik 
wawancara berstruktur, yaitu teknik wawancara dimana pewawancara menggunakan (mempersiapkan) daftar pertanyaan atau daftar isian sebagai pedoman saat melakukan wawancara (Hasan, 2002:85). Pada penelitian ini dilakukan wawancara terstrukur dan wawancara tidak terstruktur. Wawancara terstruktur yaitu mengajukan pertanyaan yang sudah terstruktur kepada pihak-pihak yang bersangkutan sedangkan wawancara tidak terstruktur yaitu responden memberikan informasi bebas tanpa terikat oleh pertanyaan dan responden dianjurkan memperinci atau memperjelas jawaban.

Adapun pertanyaan yang diajukan mengenai masalah pengembangan laksa sebagai pendukung kegiatan wisata di Tangerang sehingga dapat mendukung kelengkapan dan keakuratan data khususnya mengenai profil wisata, rencana pengembangan dan isu terkait pengembangan wisata. Pengumpulan data dengan metode wawancara ditujukan kepada instansi/ akademis serta pengusaha wisata.

\section{- Kuesioner dan Pembobotan}

Penyebaran kuesioner merupakan salah satu teknik pengumpulan data yang akan dilakukan dalam penelitian ini. Penyebaran kuesioner merupakan inti penelitian dari semua teknik pengumpulan data yang akan dilakukan, dimana hasil penyebaran kuesioner ini akan sangat berguna, yang bertujuan sebagai dasar pembuatan analisis, disamping hasil teknik pengumpulan data lainnya.

Dalam penelitian ini pengusaha dan pengrajin kuliner laksa dijadikan sebagai unit observasi dan ditentukan sebagai unit analisis dari perusahan 
yaitu adalah pihak pengambil keputusan yang sangat berpengaruh di perusahaan itu sendiri, diantaranya terkait Sumber Daya Manusia, Keuangan, Produksi, dan Pemasaran.

Untuk pembobotan digunakan data input dari hasil kuesioner untuk pembobotan. Dari kuesioner diambil suatu nilai yang didapat dari rata-rata yang diberikan responden pada setiap key success factor. Setelah didapatkan nilai, maka untuk mendapatkan bobot dilakukan pembagian antara nilai dengan total dari keseluruhan nilai pada masing-masing faktor yaitu eksternal dan internal.

Untuk key success factor yaitu dengan mengidentifikasi faktor-faktor kunci variabel dari vaktor internal baik itu kekuatan maupun kelemahan dan factor eksternal yaitu peluang dan ancaman yang menjadi indikator dari kondisi perusahaan dan memformulasikan kedalam strategi-strategi alternatif. 
Berikut tabel identifikasi operasional variabel yang digunakan dalam pengolahan data.

Tabel 1. Oprasional variable

\begin{tabular}{|c|c|c|c|}
\hline Konsep & Variable & Indikator & Item \\
\hline \multirow{8}{*}{$\begin{array}{l}\text { Matriks } \\
\text { Internal - } \\
\text { Eksternal } \\
\text { Matrik } \\
\text { Posisi } \\
\text { Strategis } \\
\text { dan } \\
\text { Evaluasi } \\
\text { Tindakan }\end{array}$} & \multirow[t]{4}{*}{$\begin{array}{l}\text { Faktor } \\
\text { Internal }\end{array}$} & \multirow[t]{4}{*}{ Kekuatan/Kelemahan } & $\begin{array}{ll}\text { Aspek Keuangan } \\
\text { - } & \text { Sumber permodalan } \\
\text { - } & \text { Pengelolaan Modal Usaha } \\
\text { - } & \text { Pengelolaan Modal Usaha } \\
\text { - } & \text { Pengelolaan }\end{array}$ \\
\hline & & & $\begin{array}{l}\text { Aspek Produksi } \\
\text { - } \text { Bahan Baku } \\
\text { - } \text { Pengolahan } \\
\text { - } \text { Penyimpanan bahan baku } \\
\text { - } \quad \text { Penyimpanan bahan jadi }\end{array}$ \\
\hline & & & $\begin{array}{l}\text { Aspek SDM } \\
-\quad \text { Kuantitas } \\
-\quad \text { Kualitas }\end{array}$ \\
\hline & & & $\begin{array}{l}\text { Aspek Pemasaran } \\
\text { - } \text { Produk } \\
\text { - } \text { Harga } \\
\text { - Network dalam pemasaran } \\
\text { - } \\
\end{array}$ \\
\hline & \multirow[t]{4}{*}{$\begin{array}{l}\text { Faktor } \\
\text { Ekternal }\end{array}$} & Ancaman/Peluang & $\begin{array}{l}\text { Aspek pasar } \\
-\quad \text { Pertumbuhan pasar } \\
\text { - Persaingan }\end{array}$ \\
\hline & & & $\begin{array}{l}\text { Aspek dukungan pemerintah } \\
\text { - } \quad \text { Bantuan dana pengembangan } \\
\text { - Pelatihan dan pendampingan } \\
\text { - Kebijakan terkait pengembangan wisata } \\
\text { dan kuliner }\end{array}$ \\
\hline & & & $\begin{array}{l}\text { Aspek dukungan organisasi non pemerintah } \\
\text { - } \quad \text { Bantuan dana pengembangan } \\
\text { - Pelatihan dan pendampingan } \\
\end{array}$ \\
\hline & & & $\begin{array}{l}\text { Aspek dukungan akademisi } \\
\text { - Pelatihan dan pemdampinga } \\
\text { - Publikasi terkait permasalahan dalam } \\
\text { pengembangan wisata dan kuliner }\end{array}$ \\
\hline
\end{tabular}

\section{- FGD (Focus Group Discussion)}

FGD adalah suatu metode kualitatif. Tujuannya adalah untuk memperoleh informasi mendalam pada konsep, persepsi dan gagasan untuk suatu kelompok FGD mengarahkan untuk menjadi lebih dari suatu pertanyaan-pertanyaan interaksi jawaban. FGD dilakukan untuk mereduksi jenis kuliner dan mengerucutkan kepada beberapa jenis kuliner betawi yang menjadi prioritas untuk proses pengembangan lebih lanjut. 


\section{b. Survei sekunder}

Survei sekunder yang dilakukan merupakan studi kepustakaan dari bukubuku yang berhubungan dengan pokok permasalahan yang diangkat dalam penelitian serta penjelasan mengenai metode yang digunakan dalam penelitian. Mencari data melalui instansi-instansi yang berhubungan dengan penyelengaraan kegiatan pariwisata di Tangerang. Data yang dibutuhkan menyangkut data kepariwisataan di Tangerang, kondisi objek wisata, perkembangan kuliner laksa.

\section{Pengolahan Data}

\section{Tahap Masukan (Input Stage)}

Tahap ini merupakan tahap pertama merangkum hasil identifikasi faktor permasalahan-permasalahan baik faktor internal maupun faktor eksternal yang terjadi di IHT sebagai masukan penting yang dibutuhkan untuk formulasi strategi. Dalam pelaksanaannya tahap ini menggunakan matriks-matriks yang kuantitatif yang menerangkan faktor-faktor eksternal dan internal, sehingga pengembangan dan evaluasi alternatif strategi menjadi lebih efektif. Matriks-matriks tersebut adalah

\section{a. Matrik IFE (Internal Factor Evaluation)}

Matrik IFE digunakan untuk mengetahui faktor-faktor internal yang berpengaruh terhadap pengembangan ekowisata kuliner dan berkaitan dengan kekuatan dan kelemahan yang dianggap paling dominan dalam pemilihan strategi. Data dan informasi aspek internal perusahaan dapat digali dari beberapa fungsional perusahaan misalnya dari aspek pemasaran, keuangan, operasi, organisasi dan sumber daya manusia.

Adapun cara perhitungannya adalah : 
a. Jumlah $=$ total jawaban 4 responden, dst

b. Bobot = jumlah $/$ total jumlah IFE, dst

c. Rating $=$ jumlah / jumlah responden, dst

d. Score $=$ bobot $*$ Rating, dst

\section{b. Matrik EFE (External Factor Evaluation)}

Matrik EFE digunakan untuk mengevaluasi faktor-faktor eksternal dalam pengembangan ekowisata kuliner. Data eksternal dikumpulkan untuk menganalisis hal-hal yang menyangkut persoalan politik, ekonomi, sosial, pesaing dan konsumen/pelanggan, hal ini penting karena faktor eksternal berpengaruh secara langsung maupun tidak langsung terhadap perusahaan.

Adapun cara perhitungannya adalah :

a. Jumlah $=$ total jawaban 4 responden, dst

b. Bobot = jumlah / total jumlah EFE, dst

c. Rating = jumlah / jumlah responden, dst

d. Score $=$ bobot $*$ Rating, dst

\section{Tahap Penyesuaian (Matching Stage)}

Tahap ini menyesuaikan sumber daya internal dengan kondisi eksternal dan mengembangkan alternatif-alternatif strategi yang tepat. Pengembangan strategi dilakukan dengan menggunakan matriks-matriks berikut :

a. Matriks Internal-External (IE)

Matriks Internal-External (IE) ini bermanfaat untuk memposisikan kegiatan ekowisata kuliner kedalam matriks yang terdiri atas 9 sel. Matriks IE ini didasarkan pada informasi yang didapat pada tahap sebelumnya dengan menggunakan hasil evaluasi dari matriks IFE dan matriks EFE dimana untuk 
sumbu horizontal pada matrik IE ini adalah total skor dari matriks IFE, sedangkan untuk sumbu matriks vertikal adalah total skor dari matriks EFE, kemudian dapat diketahui posisi kegiatan ekowisata kuliner berada di posisi sel berapa sehingga dapat ditentukan strategi apa yang seharusnya diambil,

b. Matriks SWOT

Alat analisis yang dipakai adalah SWOT (Strength, Weakness, Opportunities, Threat) yaitu kekuatan, kelemahan, peluang dan ancaman. Dalam bidang pariwisata analisis SWOT bermanfaat untuk merumuskan arahan dan strategi dalam pengembangan ekowisata kuliner. Analisis SWOT sebagai alat alat identifikasi berbagai faktor secara sistematis untuk merumuskan strategi berdasarkan logika yang dapat memaksimalkan potensi dan peluang namun secara bersamaan dapat meminimalisasi kelemahan dan ancaman sehingga akan memberikan output berupa target atau perlakuan untuk mencapai tujuan (Santosa dkk, 2002:37)

\section{HASIL DAN PEMBAHASAN}

\section{Matriks Evaluasi Faktor Internal (Internal Factor Evaluation-IFE)}

Alat perumusan strategi ini meringkas dan mengevaluasi kekuatan dan kelemahan utama dalam area-area fungsional bisnis, dan juga menjadi landasan untuk mengidentifikasi serta mengevaluasi hubungan di antara area tersebut. Penilaian intuitif digunakan dalam pengembangan Matriks Evaluasi Faktor Internal sehingga tampilan ilmiahnya tidak boleh ditafsirkan sebagai bukti bahwa teknik ini benar-benar tanpa celah. Matriks Evaluasi Faktor Internal Pengembangan laksa sebagai produk wisata kuliner yang dapat digambarkan pada tabel 3 dan 2 beserta analisis setiap faktor-faktornya, sebagai berikut: 
Tabel 2. Matrik IFA Summary

\begin{tabular}{|c|c|c|c|c|}
\hline No & Faktor - faktor Internal Utama & \multirow[t]{2}{*}{ Bobot } & \multirow[t]{2}{*}{ Rank } & \multirow{2}{*}{$\begin{array}{c}\text { Skor } \\
\text { Bobot }\end{array}$} \\
\hline \multicolumn{2}{|c|}{ Kekuatan } & & & \\
\hline 1 & Ketersediaan bahan baku & 0,10 & 4 & 0,4 \\
\hline 2 & Proses produksi & 0,04 & 2 & 0,08 \\
\hline 3 & Harga jual & 0,25 & 3 & 0,75 \\
\hline 4 & Kebersihan & 0,06 & 2 & 0,12 \\
\hline 5 & Kecepatan layanan & 0,05 & 2 & 0,1 \\
\hline 6 & Kemempuan dalam tata kelola keuangan & 0,10 & 3 & 0,3 \\
\hline \multicolumn{2}{|r|}{ Sub Total } & 0,60 & & 1,75 \\
\hline \multicolumn{2}{|c|}{ Kelemahan } & & & \\
\hline 1 & Ketersediaan tempat usaha & 0,025 & 1 & 0,025 \\
\hline 2 & Standarisasi produksi & 0,025 & 2 & 0,5 \\
\hline 3 & Ketersediaan SDM yang kompeten & 0,05 & 3 & 0,15 \\
\hline 4 & Promosi sebagai media informasi & 0,10 & 4 & 0,4 \\
\hline 5 & Ketersediaan modal & 0,20 & 4 & 0,8 \\
\hline \multicolumn{2}{|r|}{ Sub Total } & 0,40 & & 1,875 \\
\hline & Total & 1.00 & & 3,625 \\
\hline
\end{tabular}

Berdasarkan hasil analisis pada tabel 1 menunjukkan bahwa IFAS faktor strength mempunyai total nilai skor 1,75 sedangkan weakness mempunyai skor 1,875. Seperti hanya dalam IFAS maka pada faktor - faktor strategi ekternal EFAS juga dilakukan identifikasi yang hasilnya tertuang dalam table berikut.

Tabel 3. Matrik EFA Summary

\begin{tabular}{|c|c|c|c|c|}
\hline No & Faktor-faktor Eksternal Utama & \multirow[t]{2}{*}{ Bobot } & \multirow[t]{2}{*}{ Rank } & \multirow{2}{*}{$\begin{array}{l}\text { Skor } \\
\text { Bobot }\end{array}$} \\
\hline \multicolumn{2}{|r|}{ Kesempatan } & & & \\
\hline 1 & $\begin{array}{l}\text { Perkembangan wisata secara global yang cukup } \\
\text { baik }\end{array}$ & 0,07 & 2 & 0,14 \\
\hline 2 & $\begin{array}{l}\text { Permintaan terhadap kuliner tradisional } \\
\text { khususnya laksa yang terus berkembang }\end{array}$ & 0,33 & 3 & 0,99 \\
\hline 3 & Perhatian dari pemerintah & 0,15 & 3 & 0,45 \\
\hline 4 & Banyaknya bantuan pelatihan manajemen & 0,10 & 2 & 0,20 \\
\hline & $\begin{array}{ll} & \text { Sub total } \\
\end{array}$ & 0,65 & & 1,78 \\
\hline \multicolumn{2}{|c|}{ Hambatan } & & & \\
\hline 1 & Pajak yang memberatkan & 0,10 & 1 & 0,10 \\
\hline 2 & Kurangnya bantuan dana & 0,05 & 3 & 0,15 \\
\hline 3 & Regulasi dalam pendirian usaha & 0,05 & 2 & 0,10 \\
\hline 4 & Wisata Kota Tangerang yang kurang populer & 0,15 & 4 & 0,60 \\
\hline & Sub Total & 0,35 & & 0,95 \\
\hline & Total & 1,00 & & 2,730 \\
\hline
\end{tabular}


Sedangkan dari hasil analisis pada tabel 2 menunjukkan bahwa EFAS faktor opportunity mempunyai total nilai skor 1,78 sedangkan threat mempunyai skor 2,730. Maka diketahui selisih nilai weakness dan strength adalah - 0,125 sedangkan selisih antara opportunity dan threat adalah - 0,95. Dari hasil identifikasi faktor - faktor tersebut maka dapat digambarkan dalam diagram sebagai berikut :

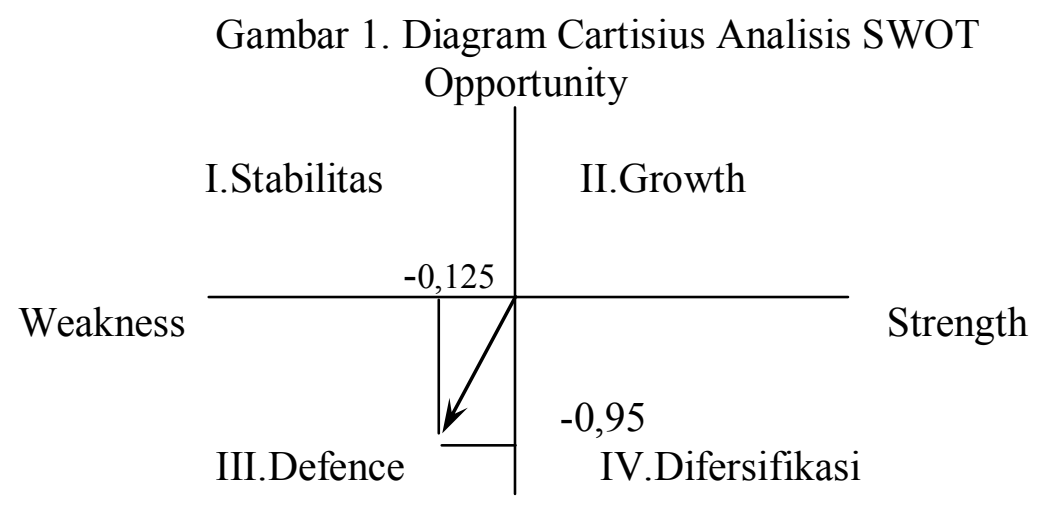

Threat

Berdasarkan gambar diatas posisi kuliner laksa adalah pada posisi defence sehingga pilihan strategi yang mungkin diterapkan adalah :

- Penetrasi pasar.

- Pengembangan pasar.

- Pengembangan produk dimana pelanggan yang sudah ada akan berminat terhadap produk yang masih berkaitan hal ini dapat dilakukan dengan strategi inovasi dan diversifikasi produk.

Dari nilai total masing masing faktor selain digambarkan dengan diagram SWOT juga digambarkan dalam rumus matrik SWOT yang dapat dilihat pada table 4. 


\section{Matrik SWOT}

Dari analisis matriks IFAS dan EFAS pada tabel 1 dan 2 telah disusun pula matriks SWOT untuk menganalisis rumusan alternatif strategi yaitu SO, WO, ST dan WT. Penjelasan dari masing - masing strategi dapat dilihat dapat tabel berikut :

Tabel 4. Kombinasi Strategi Matrik SWOT

\begin{tabular}{|c|c|c|}
\hline EFAS & 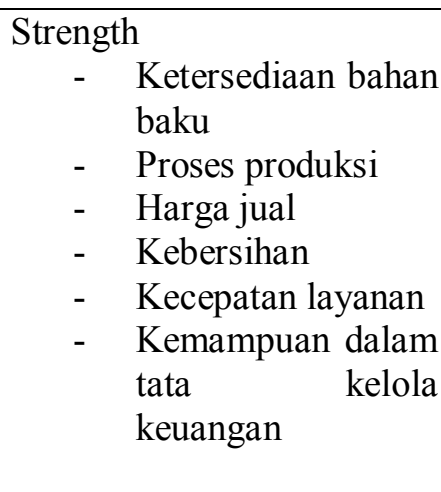 & $\begin{aligned} & \text { Weakness } \\
& \text { - } \text { Ketersediaan } \\
& \text { tempat usaha } \\
&- \text { Standarisasi } \\
& \text { produksi } \\
&- \text { Ketersediaan SDM } \\
& \text { yang kompeten } \\
&- \text { Promosi sebagai } \\
& \text { media informasi } \\
&- \text { Ketersediaan } \\
& \text { modal }\end{aligned}$ \\
\hline 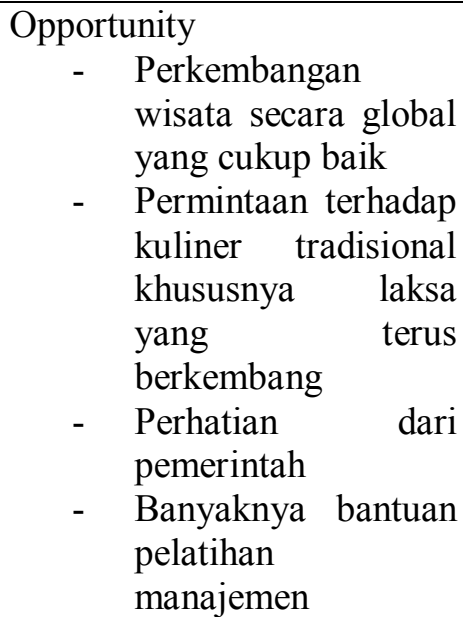 & $\begin{array}{ll}\text { SO } & \\
\text { - } & \text { Pengelola wisata } \\
\text { kuliner } \\
\text { mengikatkan } \\
\text { dirinya secara kuat } \\
\text { pada produk dan } \\
\text { pasarnya yang } \\
\text { sudah terbentuk } \\
\text { dan ada saat ini } \\
\text { - Melakukan inovasi } \\
\text { dan difersivikasi } \\
\text { produk }\end{array}$ & $\mathrm{WO}$ \\
\hline $\begin{array}{cll}\text { Threat } & \\
\text { - } & \text { Pajak yang } \\
& \text { memberatkan } \\
\text { - } & \text { Kurangnya bantuan } \\
& \text { dana } \\
\text { - } & \text { Regulasi dalam } \\
& \text { pendirian usaha } \\
\text { - } & \text { Wisata Kota } \\
& \text { Tangerang yang } \\
& \text { kurang populer }\end{array}$ & TS & WT \\
\hline
\end{tabular}

Sedangkan untuk backward integration, forward integration dan horizontal integration kurang reliable untuk dilakukan saat ini mengingat key 
factor yang didapat dalam penelitian tidak mengarahkan pada permasalahan yang terkait tiga hal tersebut.

\section{KESIMPULAN}

Berdasarkan analisis diatas dapat disimpulkan bahwa kuliner laksa yang merupakan kuliner tradisional adalah alternatif pengembangan wisata yang cukup potensial untuk dikembangkan di Tangerang. Terkait hal tersebut, pengembangan kuliner Laksa Tangerang dengan membangun strategi untuk mendukung kegiatan bisnisnya menjadi hal yang perlu untuk diformulasikan.

Dari penelitian diatas didapatkan beberapa alternatif strategi pengembangan bisnis restoran kuliner Betawi yaitu :

1. Penetrasi pasar dengan menentukan sebuah target khusus untuk memantapkan posisioning kuliner Betawi, sehingga dapat lebih fokus dalam menentukan kebijakan terkait pemasaran secara lebih lanjut.

2. Pengembangan produk dengan menciptakan inovasi produk kuliner dan membuat diversifikasi produk kuliner Betawi untuk menyesuaikan produk dengan keinginan pasar dan konsumen.

3. Memilih produk-produk yang sudah dan ada akan diterima dengan baik oleh kelompok pelanggan baru.

\section{DAFTAR PUSTAKA}

Akurinto, 2002, Metode Statsitik Untuk Bisnis dan Ekonomi. Edisi pertama. PT. Gramedia. Pustaka Utama, Jakarta 
Dewi, Ike Juwita, 2011, Implementasi dan Implikasi Kelembagaan Pemasaana Pariwisata yang Bertanggung Jawab (Responsible Tourism Marketing), Kementrian Kebudayaan dan Pariwisata Republik Indonesia.

Kardigantara, Suseno dan Goeltom, Andar Danova, 2007, Pengembangan Potensi Wisata Kuliner Di Bandung. Warta Pariwisata [Media Cetak], 9/I/Maret 2007.

Santoso dan Tjiptono, 2004, Riset Pemasaran Konsep dan Aplikasi dengan SPSS, PT Elex Media Komputindo, Jakarta.

Sugiyono, 2011, Statistika Untuk Penelitian Penerbit Alfabeta, Bandung Husein Umar, 2008, Metode Riset Bisnis, PT Gramedia Pustaka Utama, Jakarta.

Hasan, Iqbal, 2002, Pokok-pokok Materi Metodologi Penelitian dan Aplikasinya, Jakarta: Ghalia Indonesia.

Nazir, Moch, 2003, Metode Penelitian, Salemba Empat, Jakarta.

Virna, 2007, Wisata Kuliner, Warta Pariwisata, Institut Teknologi Bandung, Bandung. 